\title{
Renoprotective effect of curcumin against the combined oxidative stress of diabetes and nicotine in rats
}

\author{
ZEIN SHABAN IBRAHIM ${ }^{1,2}$, MOHAMED ELSAYED ALKAFAFY ${ }^{3,4}$, \\ MOHAMED MOHAMED AHMED ${ }^{3,5}$ and MOHAMED MOHAMED SOLIMAN ${ }^{6,7}$
}

\author{
${ }^{1}$ Department of Physiology, College of Medicine, Taif University, Al-Hawiyah, Taif 21944, Saudi Arabia; \\ ${ }^{2}$ Department of Physiology, Faculty of Veterinary Medicine, Kafrelsheikh University, Kafr El-Sheikh 33516, Egypt \\ ${ }^{3}$ Department of Biotechnology, College of Science, Taif University, Al-Hawiyah, Taif 21944, Saudi Arabia; \\ Departments of ${ }^{4}$ Histology and ${ }^{5}$ Biochemistry, College of Veterinary Medicine, University of Sadat City, \\ Sadat City 32897, Egypt; ${ }^{6}$ Department of Medical Laboratories, College of Applied Medical Sciences, \\ Taif University, Turubah, Taif 21974, Saudi Arabia; ${ }^{7}$ Department of Biochemistry, \\ College of Veterinary Medicine, Benha University, Moshtohor, Banha 13511, Egypt
}

Received April 6, 2015; Accepted January 29, 2016

DOI: $10.3892 / \mathrm{mmr} .2016 .4922$

\begin{abstract}
The progression of diabetic nephropathy (DN) is accelerated by smoking. The current study investigated the ability of curcumin to protect the kidneys against damage from oxidative stress induced by diabetes mellitus (DM) and nicotine (NC). A total of 24 male Wistar rats were divided into four groups of six rats each. DM was induced by a single intraperitoneal injection of streptozotocin $60 \mathrm{mg} / \mathrm{kg}$ body weight. DM rats were treated with or without $\mathrm{NC}$ in the absence or presence of curcumin for 8 weeks. As compared with the controls, DM rats exhibited reduced serum levels of high density lipoprotein, superoxide dismutase and glutathione peroxidase, and decreased renal mRNA expression levels of synaptopodin, connexin 43 and erythropoietin (EPO), which were further suppressed by $\mathrm{NC}$ and restored to normal levels by curcumin treatment. Additionally, DM rats exhibited increases in their lipid profiles (cholesterol, triacylglycerol and phospholipids), oxidative markers (malondialdehyde,
\end{abstract}

Correspondence to: Dr Zein Shaban Ibrahim, Department of Physiology, College of Medicine, Taif University, Al-Hawiyah, Al-Steen Street, Taif 21944, Saudi Arabia

E-mail: zainibrahim2012@yahoo.com

Abbreviations: DN, diabetic nephropathy; STZ, streptozotocin; HDL, high density lipoprotein; SOD, superoxide dismutase; GPx, glutathione peroxidase; SPD, synaptopodin; Cx43, connexin 43; EPO, erythropoietin; TG, triacylglycerol; MDA, malondialdehyde; GGT, $\gamma$-glutamyltranspeptidase or glutathione hydrolase; SREBP-1, sterol regulatory element binding protein 1 ; iNOS, inducible nitric oxide synthase; TGF- $\beta 1$, transforming growth factor $\beta 1$; DM, diabetes mellitus; EMT, epithelial-mesenchymal transition; ECM, extracellular matrix

Key words: diabetes, nicotine, curcumin, kidney, rat $\gamma$-glutamyltranspeptidase and nitric oxide), kidney function markers (urea and creatinine) and the mRNA expression levels of vimentin, desmin, SREBP-1, iNOS and TGF- $\beta 1$. These effects were further enhanced by NC, but counteracted by curcumin treatment. Kidneys from DM rats displayed glomerular hypertrophy, sclerosis and tubulo-interstitial changes represented by tubular lipid deposition, interstitial mononuclear cell infiltration and fibroplasia. Pancreatic islets exhibited cellular vacuolation, morphological irregularity and damaged or reduced in size $\beta$-cells. These renal and pancreatic changes became more severe following $\mathrm{NC}$ treatment and were ameliorated by curcumin. Therefore, NC-induced DN progression may predominantly operate by increasing oxidative stress, reducing the levels of antioxidants, suppressing EPO levels, and causing perturbations to gap junction and podocyte structure. Curcumin may ameliorate the damaging effects of DM and NC on the kidney through normalization of the mRNA expression levels of several genes important in the progression of DN.

\section{Introduction}

Diabetic nephropathy (DN) is a common complication of diabetes mellitus (DM), which is a major health problem worldwide (1). Chronic inflammation and oxidative stress are crucial contributors to the progression of DN (2). Various preventable factors, including hypertension, alcoholism and smoking, also accelerate DN progression. Epidemiological studies suggest that cigarette smoking increases the progression rate of renal failure among insulin-and non-insulin-dependent patients with DM (3), and is associated with elevated serum creatinine levels (4). A dose-dependent relationship between the number of cigarettes smoked and the development of albuminuria was reported in type $1 \mathrm{DM}$ (5). Additionally, the prevalence of microalbuminuria and macroalbuminuria was significantly higher in patients with type $2 \mathrm{DM}$ that were smokers. A possible role of smoking in the acceleration of renal remodeling and 
damage was postulated to operate via a mechanism independent of the damage caused by DM (6). Evidence from the European population indicates that smoking may be associated with the progression of chronic kidney disease (CKD), particularly in men (7).

Previous studies have focused on anti-inflammatory and anti-oxidative treatments as a method to delay the progression of glomerulopathy $(2,8)$. Curcumin, derived from the rhizome of the herb Curcuma longa, has been indicated to possess a variety of beneficial effects, including anti-inflammatory and anti-oxidative activities (9). Curcumin has been demonstrated to be protective against nephropathy and islet damage in streptozotocin (STZ)-induced diabetic rats $(10,11)$. Curcumin was previously reported to be effective in preventing glucose-induced oxidative stress in the endothelial cells and hearts of diabetic animals (12).

The current study aimed to investigate the potential protective effects of curcumin against the combined oxidative stress of DM and nicotine (NC), a major component of cigarette smoke.

\section{Materials and methods}

Animals. A total of 24 adult male Wistar rats (65-70 days old, 190-220 g) were purchased from the Experimental Animal Center, Faculty of Pharmacy, King Saud University (Riyadh, Saudi Arabia). Animals were housed in the animal facility of the College of Science, Taif University (Taif, Saudi Arabia) at $22^{\circ} \mathrm{C}$ and $55 \%$ humidity with a $12 \mathrm{~h}$ light/dark cycle. The rats were fed a standard pellet diet and provided with water ad libitum. The present study was approved by the ethical committee of Taif University.

Reformation of animal food with the addition of curcumin. As curcumin is water insoluble, it was added to the food of the animals at a concentration of $1.5 \mathrm{~g} / \mathrm{kg}$ of food. The food pellet was crushed to a powder and mixed thoroughly with curcumin powder (Nature's Purest, West Los Angeles, CA, USA). A small volume of water was added to create a paste and the pellets were reformed. The pellets were left to air dry for 4 days. The concentration of curcumin was selected based on the average body weight of the rats $(\sim 200 \mathrm{~g})$ and the estimated average daily feed consumption ( 25-30 g/day). The NC (Merck Millipore, Darmstadt, Germany) concentration was also selected according to the average body weight and the average daily water consumption ( $25 \mathrm{ml} /$ day $)$.

Experimental design. Following 1-week acclimatization, the rats were divided into 2 groups as follows: 18 rats were fasted for $8 \mathrm{hrs}$, after which they were injected intraperitonealy with a single dose of streptozotocin (STZ; $60 \mathrm{mg} / \mathrm{kg}$ body weight; Sigma-Aldrich, St. Louis, MO, USA) freshly dissolved in citrate buffer ( $\mathrm{pH} 4.5$ ); and a negative control group (6 rats) were injected with an equivalent volume of vehicle (citrate buffer, $\mathrm{pH} 4.5$ ). Following injection, the rats were provided with free access to food and water, and were given a $5 \%$ glucose solution to drink overnight to counteract hypoglycemic shock. DM in the rats was identified by moderate polydipsia and marked polyuria. After 3 days, the fasting blood glucose levels were measured in tail blood samples (Accu-Chek Aviva Blood
Glucose Meter; Roche Diagnostics, Indianapolis, IN, USA). The rats with glucose levels $>200 \mathrm{mg} / 100 \mathrm{ml}$ were considered to be diabetic and selected for further experimentation. The diabetic rats were divided into three groups of six rats each as follows: i) The DM group; ii) the DM + NC group; and iii) the $\mathrm{DM}+\mathrm{NC}+$ curcumin group. $\mathrm{NC}$ was added to the drinking water of the $\mathrm{DM}+\mathrm{NC}$ and the $\mathrm{DM}+\mathrm{NC}+$ curcumin group rats at a concentration of $12 \mu \mathrm{g} / \mathrm{ml}$ to attain a treatment dose of $1.5 \mathrm{mg} / \mathrm{kg}$ body weight. The food of the $\mathrm{DM}+\mathrm{NC}+$ curcumin group rats was additionally supplemented with curcumin at a concentration of $1.5 \mathrm{~g} / \mathrm{kg}$ body weight to obtain a final concentration of $1.5 \mathrm{mg} / \mathrm{kg}$ body weight. Treatments were continued for the 8 weeks following induction of DM. Random blood glucose levels were measured from tail blood samples every week to ensure the rats remained diabetic. At the end of the experiment, the rats were fasted for $8 \mathrm{~h}$ and anesthetized with diethyl ether ( $\geq 99.0 \%$; Sigma-Aldrich), while blood samples were taken from the medial canthus of the eyes into heparinized tubes. The rats were sacrificed by head dislocation and tissue samples were taken for RNA extraction and stored at $-80^{\circ} \mathrm{C}$ prior to use. Samples for histological examination were stored in $10 \%$ formalin (Sigma-Aldrich) until processing.

Biochemical analysis. Urea and plasma creatinine assays were performed using the UREA liquicolor (cat. no. 10505) and CREATININE liquicolor (cat. no. 10051) Complete Test kits purchased from HUMAN Gesellschaft für Biochemica und Diagnostica mbH (Wiesbaden, Germany). Cholesterol, triacylglycerol (TG) and high density lipoprotein (HDL) levels were measured using kits (cat. nos. 024-100, 059L-050 and 041-050, respectively) purchased from United Diagnostics Industry (Dammam, Saudi Arabia). Commercial kits were purchased from Nanjing Jiancheng Bioengineering Research Institute (Nanjing, China) to measure the levels of plasma malondialdehyde (MDA; A003-1), and the activities of $\gamma$-glutamyltranspeptidase (GGT), superoxide dismutase (SOD; A001-1) and glutathione peroxidase (GPx; A005). The plasma phospholipid levels were determined using the Phospholipid Assay kit (MAK122; Sigma-Aldrich), according to the manufacturer's protocol. The concentrations of the measured biochemical constituents were calculated according to the manufacturer's instructions.

RNA extraction. For preparation of total RNA, $50 \mathrm{mg}$ of kidney tissue sample was homogenized in $1 \mathrm{ml}$ QIAzol (Qiagen, Inc., Valencia, CA, USA) and $0.3 \mathrm{ml}$ chloroform (Nanjing Jiancheng Bioengineering Research Institute) was added to the homogenate. The mixtures were then shaken for $30 \mathrm{sec}$ followed by centrifugation at $4^{\circ} \mathrm{C}$ and $12,000 \mathrm{x}$ g for $20 \mathrm{~min}$. The supernatant layers were transferred to a new set of tubes, and an equal volume of isopropanol (Sigma-Aldrich) was added to the samples. The samples were shaken for $15 \mathrm{sec}$ and centrifuged at $4^{\circ} \mathrm{C}$ and $12,000 \mathrm{x}$ g for $15 \mathrm{~min}$. The RNA pellets were washed with $70 \%$ ethanol, briefly dried and dissolved in diethylpyrocarbonate (DEPC) water. The prepared RNA integrity was determined by $1.5 \%$ agarose gel electrophoresis. The RNA concentration and purity were determined spectrophotometrically at $260 \mathrm{~nm}$ using the GelDoc-It Imaging System (UVP, Inc., Upland, CA, USA). The ratio of the 260/280 nm optical density of all RNA samples was 1.7-1.9. 
Table I. Primers and polymerase chain reaction conditions used for the tested genes.

\begin{tabular}{|c|c|c|c|c|c|}
\hline Gene & $\begin{array}{l}\text { Product } \\
\text { size (bp) }\end{array}$ & $\begin{array}{l}\text { Annealing } \\
\text { temperature }\left({ }^{\circ} \mathrm{C}\right)\end{array}$ & Cycles & Primer & Sequence $\left(5^{\prime}-3^{\prime}\right)$ \\
\hline GAPDH & 309 & 52 & 25 & $\begin{array}{c}\text { Sense } \\
\text { Antisense }\end{array}$ & $\begin{array}{l}\text { AGATCCACAACGGATACATT } \\
\text { TCCCTCAAGATTGTCAGCAA }\end{array}$ \\
\hline Vimentin & 190 & 55 & 30 & $\begin{array}{c}\text { Sense } \\
\text { Antisense }\end{array}$ & $\begin{array}{l}\text { GAGTCAAACGAATACCGGAGAC } \\
\text { GTGGTGCTGAGAAGTCTCATTG }\end{array}$ \\
\hline Desmin & 420 & 54 & 28 & $\begin{array}{c}\text { Sense } \\
\text { Antisense }\end{array}$ & $\begin{array}{l}\text { TCACAATCACCTCTTTGTGGTC } \\
\text { CAGCACCTTCCAGTTCTCTCTT }\end{array}$ \\
\hline Synaptopodin & 457 & 59 & 32 & $\begin{array}{c}\text { Sense } \\
\text { Antisense }\end{array}$ & $\begin{array}{l}\text { ACGCCCACTAAGGTGTATAGTGA } \\
\text { CTTCCAAAATTCCTGTCTTGTTG }\end{array}$ \\
\hline Connexin 43 & 435 & 59 & 30 & $\begin{array}{c}\text { Sense } \\
\text { Antisense }\end{array}$ & $\begin{array}{l}\text { TACTTGGCCCATGTGTTCTATG } \\
\text { AACGCCTTTGAAGAAGACGTAG }\end{array}$ \\
\hline SREBP-1c & 191 & 58 & 28 & $\begin{array}{c}\text { Sense } \\
\text { Antisense }\end{array}$ & $\begin{array}{l}\text { GGAGCCATGGATTGCACATT } \\
\text { AGGAAGGCTTCCAGAGAGGA }\end{array}$ \\
\hline TGF- $\beta 1$ & 304 & 58 & 30 & $\begin{array}{c}\text { Sense } \\
\text { Antisense }\end{array}$ & $\begin{array}{l}\text { TGAGTGGCTGTCTTTTGACG } \\
\text { TGGTTGTAGAGGGCAAGGAC }\end{array}$ \\
\hline Erythropoietin & 530 & 60 & 29 & $\begin{array}{c}\text { Sense } \\
\text { Antisense }\end{array}$ & $\begin{array}{l}\text { TACGTAGCCTCACTTCACTGCTT } \\
\text { GCAGAAAGTATCCGCTGTGAGTGTTC }\end{array}$ \\
\hline iNOS & 378 & 59 & 32 & $\begin{array}{c}\text { Sense } \\
\text { Antisense }\end{array}$ & $\begin{array}{l}\text { GGTGTTCTTTGCTTCTGTGCTA } \\
\text { TGAGACAGTTTCTGGTCGATGT }\end{array}$ \\
\hline
\end{tabular}

SREBP-1c, sterol regulatory element binding protein 1 ; TGF- $\beta 1$, transforming growth factor $\beta 1$; iNOS, inducible nitric oxide synthase.

cDNA synthesis. DNase treatment of the extracted RNA was performed prior to cDNA synthesis using the RQ1 RNase-Free DNase kit (M6101; Promega Corporation, Madison, WI, USA). For synthesis of cDNA, a mixture of $2 \mu \mathrm{g}$ total RNA and 0.5 ng Oligo (dT)15 primers (Macrogen, Inc., Seoul, Korea) in a total volume of $11 \mu \mathrm{l}$ sterilized DEPC water was incubated in the Thermo Hybaid PXE 0.2 Thermal Cycler (Thermo Fisher Scientific, Inc., Waltham, MA, USA) at $70^{\circ} \mathrm{C}$ for $10 \mathrm{~min}$ for denaturing. Subsequently, $4 \mu 1$ 5X RT-buffer, $2 \mu 110 \mathrm{mM}$ dNTPs and 100 units RevertAid Premium reverse transcriptase (Fermentas; Thermo Fisher Scientific, Inc., Pittsburgh, PA, USA) were added to the reaction mixture and DEPC water was used to bring the total volume to $20 \mu \mathrm{l}$. The mixture was then incubated in the thermal cycler at $30^{\circ} \mathrm{C}$ for $10 \mathrm{~min}, 42^{\circ} \mathrm{C}$ for $1 \mathrm{~h}$ and $90^{\circ} \mathrm{C}$ for $10 \mathrm{~min}$. The resulting cDNA was then preserved at $-20^{\circ} \mathrm{C}$ until use.

Semi-quantitative polymerase chain reaction $(P C R)$. The mRNA expression levels of gene markers of kidney damage, kidney protection and integrity, and inflammation and fibrosis were analyzed by semi-quantitative PCR using the corresponding gene-specific primers (Table I). The genes analyzed were vimentin, desmin, synaptopodin (SPD), connexin 43 (Cx43), sterol regulatory element-binding protein-1c(SREBP-1c), transforming growth factor $\beta 1$ (TGF- $\beta 1$ ) and erythropoietin (EPO). As a reference gene, the expression of GAPDH mRNA was determined. The primers were designed using the Oligo Primer Analysis software, version 4 (www.oligo.net) and nucleotide sequences published in Genbank (www.ncbi.nlm. nih.gov/genbank; Table I). The primers were synthesized by Macrogen, Inc. PCR was conducted in a final reaction volume of $25 \mu \mathrm{l}$ consisting of $1 \mu \mathrm{l} \mathrm{cDNA}, 1 \mu \mathrm{l}$ of each $10 \mathrm{pM}$ forward and reverse primers, $12.5 \mu 1$ PCR master mix (Promega Corporation) and nuclease-free deionized water. PCR was conducted using the thermal cycler with a cycle sequence of denaturing at $94^{\circ} \mathrm{C}$ for $4 \mathrm{~min}$ for 1 cycle, followed by 25-32 cycles of denaturation at $94^{\circ} \mathrm{C}$ for $1 \mathrm{~min}$, annealing at the specific temperature corresponding to each primer (see Table I) and extension at $72^{\circ} \mathrm{C}$ for $1 \mathrm{~min}$, with an additional final extension step at $72^{\circ} \mathrm{C}$ for $5 \mathrm{~min}$. A pilot study was performed to optimize the specific number of cycles for each gene according to its expression level. The PCR products were electrophoresed on a $1 \%$ agarose A (Bio Basic Canada, Inc., Markham, ON, Canada) gel in Tris-EDTA buffer at $100 \mathrm{~V}$ for $30 \mathrm{~min}$, and stained with ethidium bromide. The PCR products were visualized under UV light and images were captured using the GelDoc-It Imaging System. The intensities of the bands were densitometrically quantified using NIH Image software (National Institutes of Health, Bethesda, MD, USA; rsb.info.nih.gov/nih-image).

Histological examination. Small specimens $(1.5 \times 0.5 \mathrm{~cm})$ from the pancreas and kidneys were fixed in $10 \%$ neutral-buffered formalin (Sigma-Aldrich) for $24 \mathrm{~h}$, then washed under a running tap and preserved in $70 \%$ ethanol. The samples were dehydrated in ascending grades of ethanol,cleared in xylene (Sigma-Aldrich), embedded in Paraplast Plus (Sigma-Aldrich) and sectioned to $5 \mu \mathrm{m}$ thickness. Tissue sections were mounted onto positively charged, coated slides (Thermo Fisher Scientific, Inc.). Sections were stained with hematoxylin and eosin (Sigma-Aldrich) for studying the general histological analyses (13).

Immunohistochemistry. For immunohistochemical detection of insulin granules, paraffin-embedded sections of the pancreas were deparaffinized in xylene, rehydrated in descending grades 
Table II. Serum biochemical analysis.

\begin{tabular}{|c|c|c|c|c|}
\hline Parameter & Control & $\mathrm{DM}$ & $\mathrm{DM}+\mathrm{NC}$ & $\mathrm{DM}+\mathrm{NC}+\mathrm{Cr}$ \\
\hline Glucose (mg/dl) & $101.00 \pm 0.70$ & $479.30 \pm 50.00^{\mathrm{a}}$ & $416.00 \pm 49.50^{\mathrm{a}}$ & $483.30 \pm 47.10^{\mathrm{a}}$ \\
\hline Superoxide dismutase (U/ml) & $11.67 \pm 0.16$ & $7.94 \pm 0.17^{\mathrm{a}}$ & $5.80 \pm 2.00^{\mathrm{a}, \mathrm{b}}$ & $10.73 \pm 0.30^{c}$ \\
\hline Glutathione peroxidase (U/ml) & $115.67 \pm 3.80$ & $85.67 \pm 3.30^{\mathrm{a}}$ & $69.00 \pm 0.71^{\mathrm{a}, \mathrm{b}}$ & $105.30 \pm 9.40^{c}$ \\
\hline Malondialdehyde (nmol/ml) & $3.00 \pm 0.80$ & $4.40 \pm 2.10$ & $8.74 \pm 1.20^{\mathrm{b}}$ & $3.63 \pm 0.16^{\mathrm{c}}$ \\
\hline$\gamma$-Glutamyltranspeptidase (U/l) & $4.91 \pm 0.50$ & $7.53 \pm 0.41^{\mathrm{a}}$ & $10.50 \pm 0.71^{\mathrm{a}, \mathrm{b}}$ & $6.10 \pm 1.10^{c}$ \\
\hline Cholesterol (mg/dl) & $72.30 \pm 2.59$ & $95.30 \pm 0.47^{\mathrm{a}}$ & $114.00 \pm 0.71^{\mathrm{a}, \mathrm{b}}$ & $79.70 \pm 0.94^{c}$ \\
\hline Triacylglycerol (mg/dl) & $52.30 \pm 8.00$ & $63.30 \pm 12.50$ & $81.70 \pm 4.50^{\mathrm{a}, \mathrm{b}}$ & $61.70 \pm 14.00^{c}$ \\
\hline High density lipoprotein (mg/dl) & $18.70 \pm 1.20$ & $15.30 \pm 0.50^{\mathrm{a}}$ & $11.30 \pm 1.20^{\mathrm{a}, \mathrm{b}}$ & $21.00 \pm 1.01^{\mathrm{c}}$ \\
\hline Phospholipid (mg/dl) & $91.00 \pm 2.80$ & $94.70 \pm 3.80$ & $122.30 \pm 4.00^{\mathrm{a}, \mathrm{b}}$ & $92.70 \pm 12.90^{\mathrm{c}}$ \\
\hline Urea $(\mathrm{mg} / \mathrm{dl})$ & $68.30 \pm 9.33$ & $95.00 \pm 4.95^{\mathrm{a}}$ & $138.00 \pm 24.75^{\mathrm{a}, \mathrm{b}}$ & $85.33 \pm 21.50^{b}$ \\
\hline Creatinine (mg/dl) & $1.09 \pm 0.07$ & $2.30 \pm 0.061^{\mathrm{a}}$ & $2.88 \pm 0.18^{\mathrm{a}, \mathrm{b}}$ & $1.60 \pm 0.23^{c}$ \\
\hline Nitric oxide $(\mu \mathrm{mol} / \mathrm{l})$ & $22.70 \pm 1.70$ & $62.00 \pm 4.70^{\mathrm{a}}$ & $39.00 \pm 0.70^{\mathrm{b}}$ & $28.70 \pm 0.30^{c}$ \\
\hline
\end{tabular}

Values are presented as the mean \pm standard error $(\mathrm{n}=8)$. ${ }^{\mathrm{a}} \mathrm{P}<0.05$ vs. the control group; ${ }^{\text {b }}<0.05$ vs. the $\mathrm{DM}$ group; ${ }^{\mathrm{c}} \mathrm{P}<0.05$ vs. the $\mathrm{DM}+\mathrm{NC}$ group. DM, diabetes mellitus; $\mathrm{NC}$, nicotine; $\mathrm{Cr}$, curcumin.

of alcohol and then immersed in $0.3 \%$ hydrogen peroxide (Sigma-Aldrich) for $30 \mathrm{~min}$ to inactivate endogenous peroxidase activity. The samples were heated in $10 \mathrm{mM}$ citrate buffer (Sigma-Aldrich) at $121^{\circ} \mathrm{C}$ for $30 \mathrm{~min}$ for antigen retrieval, blocked in 5\% normal serum (Sigma-Aldrich) for $20 \mathrm{~min}$, and incubated with a rabbit polyclonal anti-insulin [dilution, 1:100 in phosphate-buffered saline (PBS); sc-9168; Santa Cruz Biotechnology Inc., Dallas, TX, USA] antibody overnight at $4^{\circ} \mathrm{C}$. Subsequently, three PBS washes were performed and the sections were incubated with a goat anti-rabbit biotin-conjugated secondary antibody (dilution, 1:2,000 in PBS; sc-2040; Santa Cruz Biotechnology, Inc.) for $20 \mathrm{~min}$ at room temperature. After further incubation with horseradish peroxidase-labeled streptavidin (Vector Laboratories, Inc., Burlingame, CA, USA), the antibody binding was visualized with diaminobenzidine (Sigma-Aldrich) and sections were counterstained with hematoxylin. Negative controls, in which the primary or secondary antibodies, or the avidin-biotin complex reagent was omitted, produced no positive staining. Positive controls were used according to the instructions provided by the manufacturer's of the primary antibodies.

Photomicrography. Photomicrographs were captured using a Leica DM LB light microscope (Leica Microsystems, Inc., Buffalo Grove, IL, USA) and a Leica EC3 digital camera (Leica Microsystems, Inc.).

Statistic analysis. Statistical analysis was performed using analysis of variance and Scheffe's protected least-significant difference test on SPSS software, version 13.0 (SPSS, Inc., Chicago, IL, USA). $\mathrm{P}<0.05$ was considered to indicate a statistically significant difference. Results are expressed as the mean \pm standard error.

\section{Results}

Effect of curcumin on the plasma levels of biochemical parameters in diabetic rats. In the present study, plasma levels of the anti-oxidant enzymes, SOD and GPx, were significantly decreased in diabetic rats compared with controls (Table II), which may be caused by oxidative stress generated by the development of DM. Further reduction of these anti-oxidant enzyme levels was observed in diabetic rats treated with $\mathrm{NC}$, however, the levels were increased to a level similar to that of the control by curcumin supplementation (Table II). The plasma concentrations of the oxidative markers, MDA and $\gamma$-glutamyltranspeptidase (GGT), and the lipid profile, including cholesterol, TG and phospholipids, were increased in diabetic rats compared with control rats. This increase was enhanced by NC treatment. Curcumin supplementation reversed these effects of DM and NC. The diabetic nephropathy markers, urea and creatinine, were increased in rats of the diabetic group compared with levels in the control group. These were further enhanced in the DM + NC group, while almost normalized with curcumin supplementation.

Effect of curcumin on the mRNA expression of gene markers of kidney damage. Diabetic rats demonstrated upregulation of vimentin and desmin mRNA expression levels compared with control rats $(\mathrm{P}<0.05$; Fig. 1). Treatment of diabetic rats with $\mathrm{NC}$ decreased the expression levels of these genes compared with untreated diabetic rats $(\mathrm{P}<0.05)$, however, the expression remained increased compared with the control group $(\mathrm{P}<0.05)$. Following curcumin treatment, the DM and NC-induced upregulation of vimentin and desmin mRNA expression levels were comparable to the control group (Fig. 1).

Effect of curcumin on the mRNA expression of gap junction and podocytes integrity gene markers. Diabetic rats demonstrated no changes to SPD mRNA expression level. However, diabetic rats treated with $\mathrm{NC}$ exhibited significantly reduced SPD mRNA expression levels compared with diabetic or control rats $(\mathrm{P}<0.05$; Fig. 2A). Diabetic rats treated with $\mathrm{NC}$ and curcumin exhibited increased levels of SPD mRNA expression compared with the diabetic rats with $\mathrm{NC}$ treatment ( $\mathrm{P}<0.05$; Fig. 2A). 
A

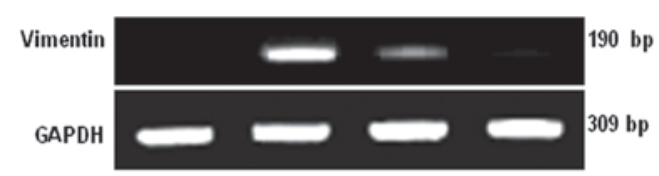

B
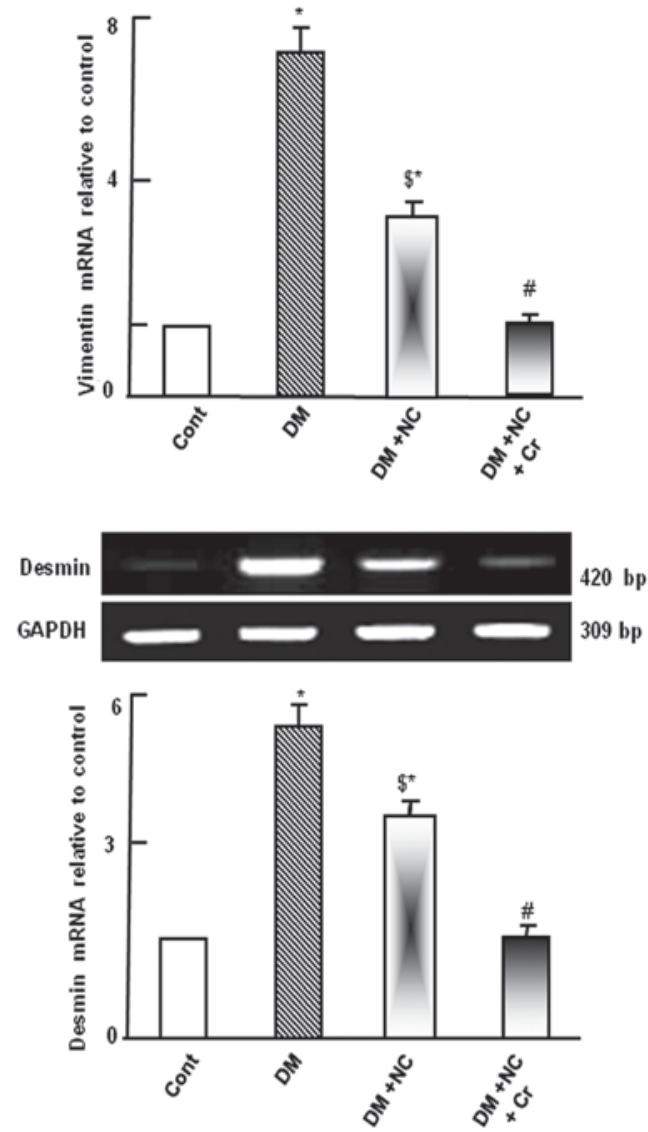

Figure 1. Effect of curcumin on diabetes-induced vimentin and desmin mRNA expression levels in kidney tissue. Total RNA was prepared from kidney tissues and the expression levels of (A) vimentin and (B) desmin were analyzed by semi-quantitative reverse transcription-polymerase chain reaction. Values are presented as the mean \pm standard error of 6 rats. ${ }^{*} \mathrm{P}<0.05$ vs. cont group; ${ }^{\$} \mathrm{P}<0.05$ vs. $\mathrm{DM}$ group; ${ }^{\#} \mathrm{P}<0.05$ vs. $\mathrm{DM}+\mathrm{NC}$ group. Cont, control; DM, diabetes mellitus; NC, nicotine; $\mathrm{Cr}$, curcumin.

DM significantly decreased the Cx43 mRNA expression compared with the control levels $(\mathrm{P}<0.05$; Fig. $2 \mathrm{~B})$. Administration of $\mathrm{NC}$ to $\mathrm{DM}$ rats resulted in a further reduction of the Cx43 mRNA expression level. However, curcumin supplementation abrogated the combined inhibitory effect of $\mathrm{DM}$ and $\mathrm{NC}$ on the Cx43 mRNA, restoring its expression, as compared with the DM + NC group ( $\mathrm{P}<0.05$; Fig. $2 \mathrm{~B})$.

Diabetic rats exhibited a downregulation of EPO mRNA expression levels compared with the control rats $(\mathrm{P}<0.05$; Fig. 2C). NC treatment of diabetic rats caused further suppression of EPO mRNA expression compared with the diabetic group $(\mathrm{P}<0.05)$. Curcumin supplementation prevented the diabetic and NC-induced suppression of EPO $(\mathrm{P}<0.05)$ and further increased EPO expression levels compared with control levels ( $\mathrm{P}<0.05$; Fig. 2C).

Effect of curcumin on mRNA expression of kidney oxidative stress markers. Diabetic rats exhibited upregulated SREBP-1c mRNA expression levels compared with control rats $(\mathrm{P}<0.05$;
A
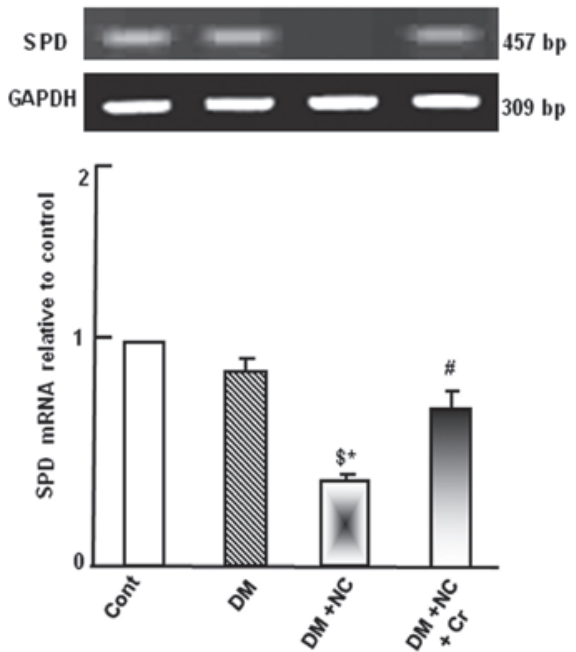

B
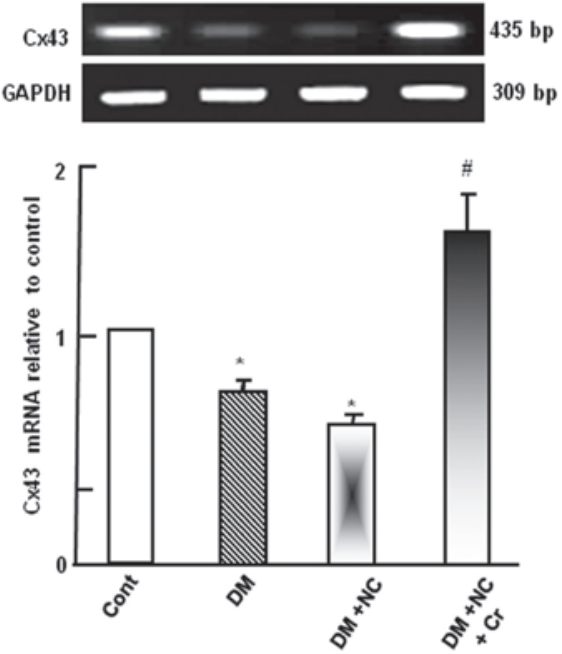

C
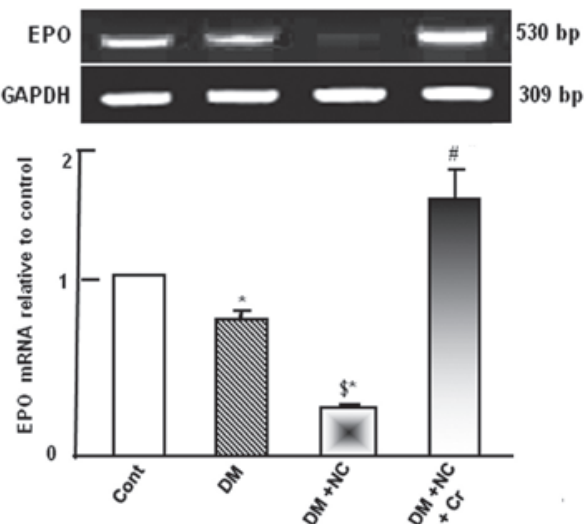

Figure 2. Effect of curcumin on mRNA expression of gene markers of gap junctions and podocyte integrity in kidney tissue. Total RNA was prepared from kidney tissues and the expression levels of (A) SPD (B) Cx43 and (C) EPO were analyzed by semi-quantitative reverse transcription-polymerase chain reaction. Values are presented as the mean \pm standard error of 6 rats. ${ }^{*} \mathrm{P}<0.05$ vs. cont group; ${ }^{\circledR} \mathrm{P}<0.05$ vs. $\mathrm{DM}$ group; ${ }^{*} \mathrm{P}<0.05$ vs. $\mathrm{DM}+\mathrm{NC}$ group. $\mathrm{SPD}$ synaptopodin; Cx43, connexin 43; EPO, erythropoietin; cont, control group; $\mathrm{DM}$, diabetes mellitus; $\mathrm{NC}$, nicotine; $\mathrm{Cr}$, curcumin.

Fig. 3A). NC treatment of diabetic rats did not demonstrate any significant change to the SREBP-1c mRNA expression compared with diabetic rats. However, the DM-induced SREBP-1c mRNA expression was abolished by curcumin 

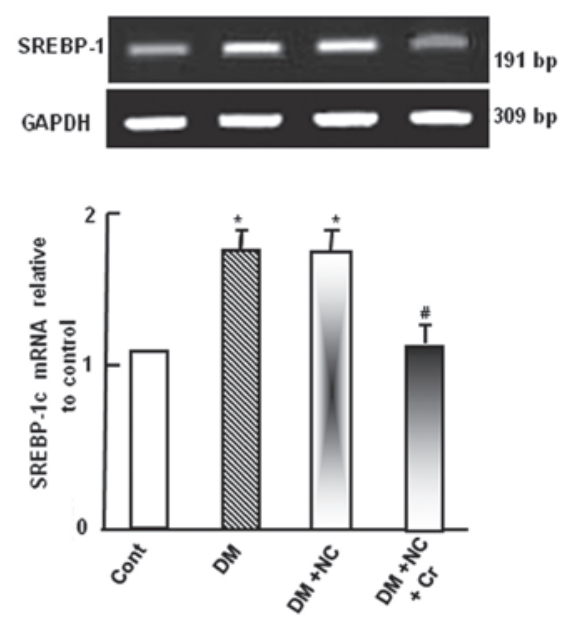

B
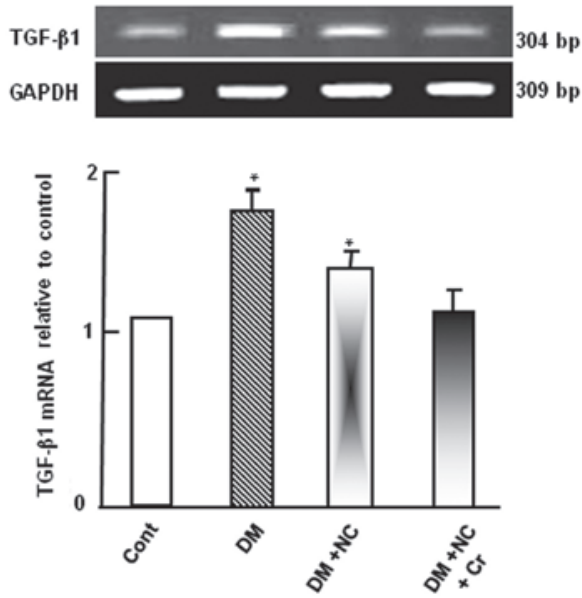

C
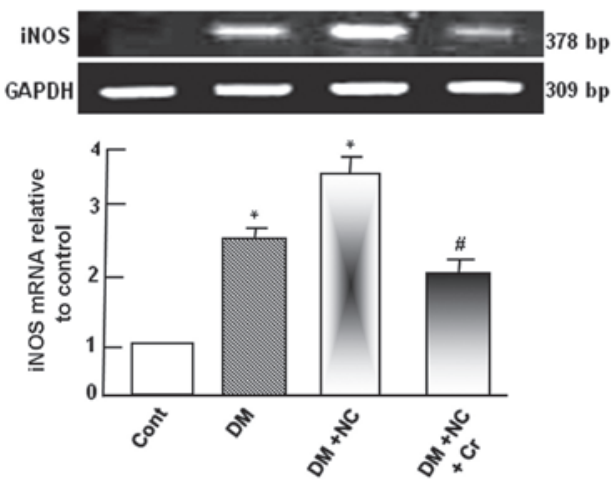

Figure 3. Effect of curcumin on mRNA expression of gene markers of kidney oxidative stress. Total RNA was prepared from kidney tissues and the expression levels of (A) SREBP-1c, (B) TGF- $\beta 1$ and (C) iNOS were analyzed by semi-quantitative reverse transcription-polymerase chain reaction. Values are presented as the mean \pm standard error of 6 rats. ${ }^{*} \mathrm{P}<0.05$ vs. cont group; ${ }^{\#} \mathrm{P}<0.05$ vs. DM + NC group. SREPB-1c, sterol regulatory element binding protein 1 ; TGF- $\beta 1$, transforming growth factor- $\beta 1$; iNOS, nitric oxide synthase; Cont, control group; DM, diabetes mellitus; $\mathrm{NC}$, nicotine; $\mathrm{Cr}$, curcumin.

supplementation, as compared with the DM + NC group $(\mathrm{P}<0.05$; Fig. 3A).

Diabetic rats exhibited a significant increase of TGF- $\beta 1$ mRNA expression levels compared with the control group $(\mathrm{P}<0.05$; Fig. 3B). NC treatment of diabetic rats decreased TGF- $\beta 1$ mRNA expression levels compared with diabetic rats,
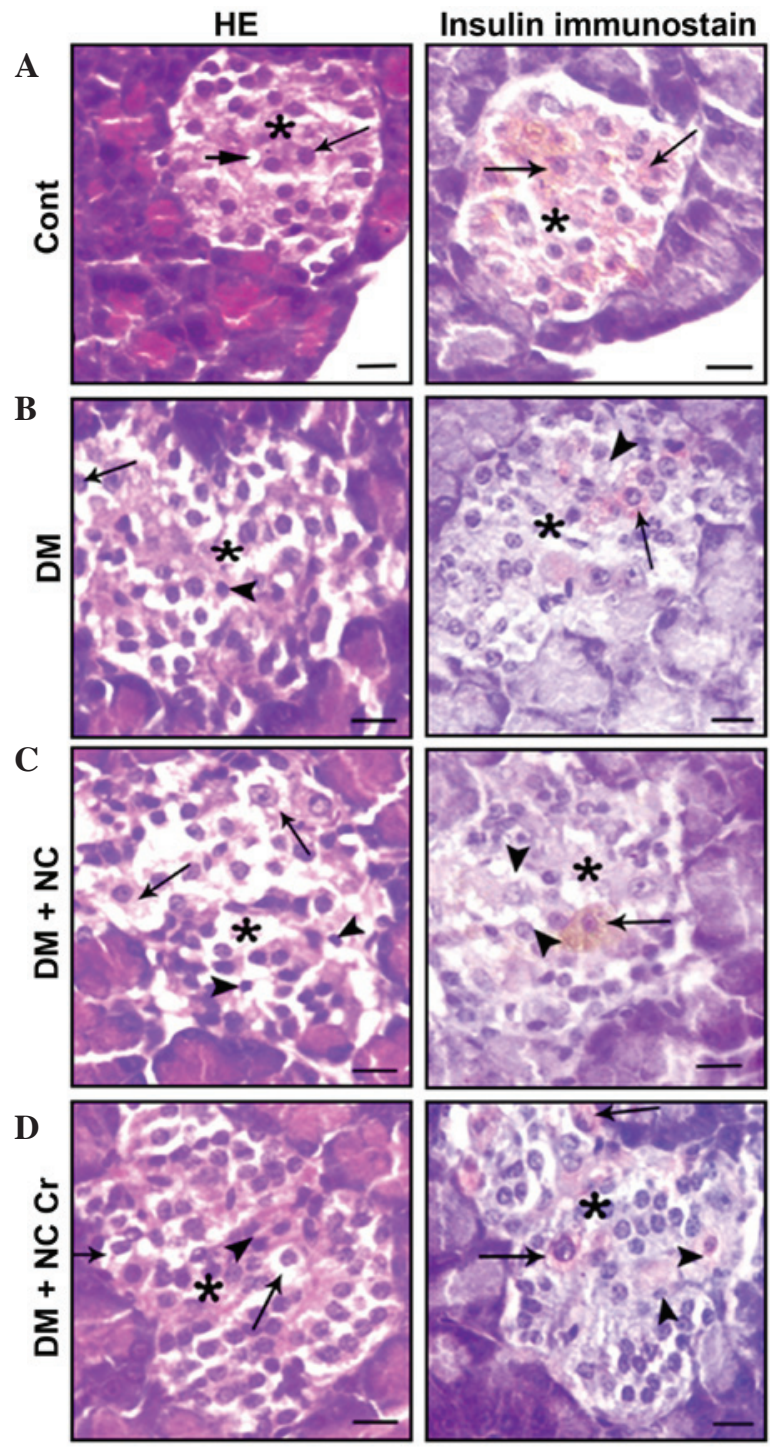

Figure 4. Effect of curcumin on pancreas histological structure. Representative images from $\mathrm{HE}$ and insulin immunostained sections from (A) control rats, (B) DM rats, (C) DM + NC rats and (D) DM + NC + Cr rats. Pancreatic islets (asterisks) and $\beta$-cells (arrows) reveal cytoplasmic vacuolations or nuclear pyknosis (arrowheads) in diabetic rats. Scale bar $=15 \mu \mathrm{m}$. $\mathrm{HE}$, hematoxylin and eosin; cont, control group; DM, diabetes mellitus; NC, nicotine; Cr, curcumin

however, the levels remained significantly higher compared with the control rats $(\mathrm{P}<0.05)$. The DM-induced increases in the TGF- $\beta 1 \mathrm{mRNA}$ expression level was significantly inhibited by curcumin supplementation, as compared with the DM + NC group $(\mathrm{P}<0.05)$, and was normalized to control levels (Fig. 3B).

Diabetic rats exhibited upregulated iNOS mRNA expression levels compared with control rats. NC treatment of diabetic rats further increased iNOS mRNA expression levels, as compared with diabetic rats. However, the increased level of iNOS mRNA was inhibited by curcumin supplementation, compared with the $\mathrm{DM}$ and NC group ( $\mathrm{P}<0.05$; Fig. 3C).

Histopathological findings. The effect of curcumin on the histological structure of the pancreas was investigated. Pancreatic sections from control rats exhibited islets of Langerhans cells, and contained lightly stained acidophilic cells arranged in branching and anastomosing cords (Fig. 4A). 

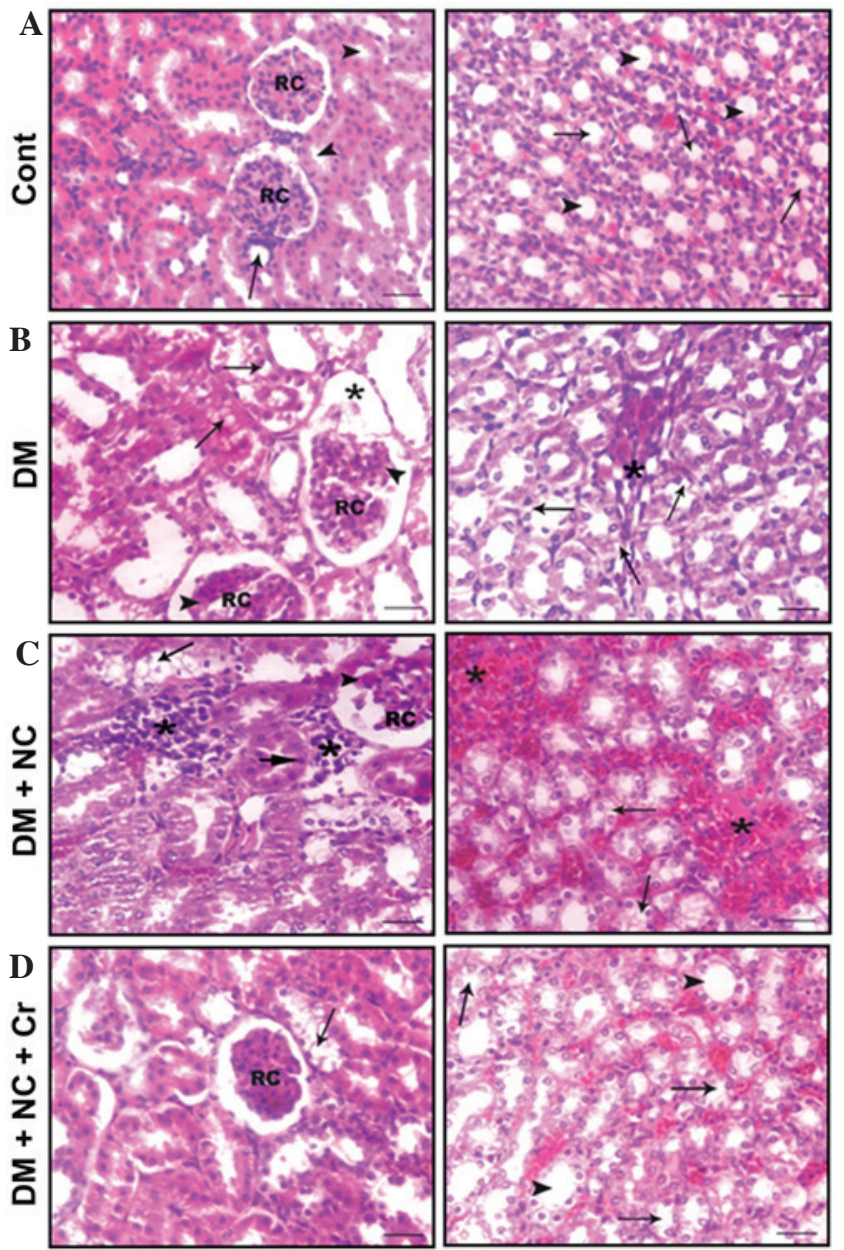

Figure 5. Effect of curcumin on the histological structure of the cortex (left panel) and medulla (right panel) of the rat kidneys (hematoxylin and eosin staining). (A) The cortex of the control rats had RC and proximal (arrowheads) and distal (arrow) convoluted tubules, and the medulla had a norma structure with thin tubules (arrows) and collecting ducts (arrowheads) (B) The cortex of the DM rats had enlarged RC, with glomerular sclerosis (arrowheads) and expansion (asterisk), and tubular lipid deposition (arrows) and dilatation. The medulla exhibited tubular dilatation, lipid deposition (arrows), interstitial nodular sclerosis and fibroplasia (asterisk). (C) The cortex from DM + NC rats had enlarged $\mathrm{RC}$, with glomerular sclerosis and expansion (arrowheads), tubular lipid deposition (arrows) and pyknosis of a number of tubular cells (long-head arrow), and interstitial leukocytic infiltration (asterisk); the medulla exhibited tubular lipid deposition (arrows) and pronounced interstitial nodular sclerosis and fibroplasia (asterisks). (D) The cortex from $\mathrm{DM}+\mathrm{NC}+\mathrm{Cr}$ rats exhibited normal sized $\mathrm{RC}$ and a lower incidence of tubular lipid deposition (arrows), and the medulla displayed a normal histological structure of thin tubules (arrows) and collecting ducts (arrowheads). Scale bar $=30 \mu \mathrm{m}$. RC, renal corpuscles; DM, diabetes mellitus; NC, nicotine; $\mathrm{Cr}$, curcumin.

Sections immunostained for the presence of insulin displayed positive $\beta$-cells within the islets (Fig. 4A). Sections from diabetic rats displayed damaged islets, represented by cytoplasmic vacuolations, pyknotic nuclei and a decrease in insulin antibody reaction (Fig. 4B). $\beta$-Cells from diabetic rats that received $\mathrm{NC}$ exhibited more severe islet alterations (Fig. 4C). Sections from diabetic rats that received $\mathrm{NC}$ and curcumin exhibited decreased $\beta$-cell damage and increased numbers of positive insulin-reacted cells (Fig. 4D).

Effect of curcumin on the kidney histological structure. Kidney sections of control rats displayed the cortex to be occupied by renal corpuscles and surrounding proximal and distal convoluted tubules (Fig. 5A, left panel), and the medulla tissue exhibited straight proximal and distal tubules, collecting ducts and thin tubules distinguished from medullary blood capillaries (Fig. 5A, right panel). Kidney tissues from DM rats displayed tissue damage, including glomerular hypertrophy, hypercellularity, mesangial expansion, pronounced glomerular sclerosis, severe tubulo-interstitial changes represented by lipid accumulation in the cortical tubules, tubular dilatation, interstitial mononuclear cell infiltration and fibroplasia (Fig. 5B). $\mathrm{NC}$ treatment further enhanced tissue damage, which was represented by increases in glomerular hypertrophy, sclerosis, mesangial expansion and severe tubulo-interstitial changes (Fig. 5C). However, curcumin treatment reduced the incidence of glomerular sclerosis, lipid accumulation and tubular dilatation compared with that of diabetic rats receiving $\mathrm{NC}$ without curcumin treatment (Fig. 5D).

\section{Discussion}

The results of the present study demonstrated vimentin and desmin mRNA levels to be upregulated in diabetic rats. This indicates tissue injury, as vimentin is an important marker of tubular epithelial-mesenchymal transition (EMT) (14). Desmin upregulation is considered to be a marker of podocyte injury (15). The downregulation of vimentin and desmin in diabetic rats by $\mathrm{NC}$ indicated that $\mathrm{NC}$-induced $\mathrm{DN}$ exaggeration may require vimentin and desmin upregulation. However, their normalization following curcumin supplementation suggested that curcumin protects against DN. The results of the current study are in agreement with a previous finding demonstrating that fasudil (a renal anti-fibrotic drug) prevented high glucose-induced EMT via decreased vimentin expression (16).

The slit diaphragm is important in the prevention of glomerular protein leakage during physiological and pathological processes (17). The slit diaphragm consists of proteins specifically expressed by podocytes, including nephrin, podocin, and SPD (18). The observation of reduced expression of SPD and Cx43 mRNA levels in diabetic rats in the present study corroborates previous studies that have demonstrated Cx43 reduction in the kidneys of STZ-diabetic rats (19) and reduced SPD expression in the glomeruli of patients with DM (20). The further downregulation of SPD and Cx43 mRNA levels by NC exposure implies that the NC-induced progression of DN may act via gap junctions and perturbation of podocytes. The reduction of SPD mRNA expression levels in diabetic rats may indicate the loss of podocytes in the urine, and its further reduction in diabetic rats treated with NC may indicate that NC increases the loss of podocytes in urine. Previous studies have demonstrated increased gene expression levels of podocyte markers, including SPD, in the urine of patients with DN, implying increased excretion of podocytes (21). The prevention of the suppressive effect of DM and NC on SPD and Cx43 mRNA levels by curcumin indicates that curcumin may protect podocytes and renal gap junctions against the oxidative stress caused by DM and smoking.

The downregulation of EPO mRNA expression levels in diabetic rats may be associated with the high risk of anemia, as patients with DN have a greater risk of developing anemia (22). 
DM-associated events in DN, such as tubulo-interstitial damage, result in the impairment of EPO production by peritubular fibroblasts, leading to the development of anemia (23). In the present study, the further suppression of EPO mRNA levels in diabetic rats exposed to $\mathrm{NC}$ indicated the ability of $\mathrm{NC}$ to increase cumulative oxidative stress and suppress EPO. Smoking during pregnancy was previously reported to be associated with a high risk of compromised child development due to maternal anemia and fetal hypoxia (24). Curcumin protected EPO mRNA expression levels from the combined inhibition by $\mathrm{DM}$ and $\mathrm{NC}$, indicating that curcumin may be able to protect the kidney from anemia caused by DM and NC. A previous study suggested that EPO administration may reduce anemia and slow the progression of CKD (25). EPO upregulation by curcumin in the current study may also represent a pathway via which curcumin mediates its reported protective activity against obesity-induced oxidative stress in mice (26).

Renal SREBP-1c upregulation is an important mechanism leading to renal TG accumulation and DN (27). In the current study, SREBP-1c mRNA upregulation was indicated, consistent with trends observed in previous studies on mesangial cells (28) and rats with type 1 DM (29). TGF- $\beta 1$ is considered as one of the main cytokines that aggravates DN (30). ECM accumulation is one of the characteristic structural abnormalities associated with DN, in addition to kidney hypertrophy and increased thickness of the glomerular basement membrane (31). In the present study, the upregulation TGF- $\beta 1$ in diabetic rats may be caused by SREBP-1c activation. Previously, high glucose-induced TGF- $\beta 1$ upregulation was demonstrated to be caused by the binding of activated SREBP-1c to the TGF promoter (28). In the current study, the partial downregulation of TGF- $\beta 1$ caused by NC in $\mathrm{DM}$ rats may indicate that $\mathrm{NC}$ is able to partially inactivate the SREBP-1c protein, as the mRNA expression level of SREBP-1c was not affected. NC was previously demonstrated to improve the serum lipid profile, decrease insulin serum levels, and to reduce steatosis and inflammation (32). The normalization of the SREBP-1 mRNA expression levels by curcumin supplementation in diabetic rats may be important for the normalization of TGF- $\beta 1$ and may represent a pathway by which curcumin protects the kidney from DN. Zhenqing recipe (a Chinese herbal prescription for improvement of renal function) has been reported to improve DN through the downregulation of SREBP-1c mRNA, which is overexpressed in rats with type $2 \mathrm{DM}$ (33). Additionally, TEMPOL (a SOD-mimicking drug) was reported to ameliorate the pathological changes in diabetic glomeruli by reducing the TGF- $\beta 1$ expression levels (34). The results of the current study indicated that $\mathrm{NC}$ has 2 opposing effects on the kidney as follows: A protective effect represented by the downregulation of vimentin and desmin expression; and a detrimental effect represented by the downregulation of SPD, Cx43 and EPO and the upregulation of iNOS mRNA expression levels. However, the net effects of $\mathrm{NC}$ on the kidney demonstrate an increase in the markers of kidney function (creatinine, urea and MDA), further reductions in the levels of GPx and SOD in the serum, and the histopathological changes to the kidney structure. These changes demonstrate the overwhelmingly destructive effects of NC. Notably, destructive effects of combined DM and NC were ameliorated by curcumin supplementation.

The morphological changes in pancreatic islets from STZ-induced diabetic rats, including cytoplasmic vacuolations, pyknotic nuclei and the decrease in insulin-positive granules, are in agreement with previous reports (35). STZ-induced DM is caused by oxidative stress on $\beta$-cells, which are particularly susceptible to oxidative insult due to their relatively low levels of antioxidants (36). NC-induced oxidative stress (37) increases the insult on the cells and may cause NC-induced $\beta$-cell apoptosis and permanent $\beta$-cell loss $(38,39)$. Abnormal lipid deposits have been previously reported in the renal cortical tubules of patients with DM (40) and have been proposed to participate in the pathogenesis of DN in STZ-induced diabetic rats (41). Curcumin amelioration of Langerhans lesions in rat pancreatic islets may be due to the anti-oxidative activity of curcumin, which may be mediated by decreased iNOS and/or increased EPO expression levels. Additionally, curcumin may exert its anti-oxidative effect via increased ROS scavenging activity through the upregulation of SOD and GPx mRNA levels. The infiltration of macrophages and mesangial accumulation of ECM proteins are commonly associated with DN (42). In a previous study, curcumin exhibited renoprotective effects in STZ-induced type $1 \mathrm{DN}$, it reduced the proteinuria and pathological changes associated with DM through the inhibition of macrophage infiltration. Curcumin was suggested to have antifibrotic and anti-inflammatory effects (43).

Increased lipid deposition in the kidney tubules of diabetic rats indicated disturbance in lipid metabolism caused by oxidative stress (44). Additional lipid deposition due to NC exposure indicated that $\mathrm{NC}$ increases oxidative stress further in DM. The increased lipid deposition in the kidney contributes to cellular damage and to the progression of DN (41). The ameliorative effect of curcumin against DM and the effects of $\mathrm{NC}$ may be due to its effects on a wide range of molecular targets that control lipid accumulation (45). Curcumin was reported to protect against DN progression through the phosphorylation of AMP-activated kinase and SREBP-1c suppression, and the reduction of renal TG accumulation (41).

In conclusion, the current study investigated the mechanisms through which curcumin protects against the combined oxidative stress of DM and NC exposure. Curcumin acts through normalizing the expression levels of various factors important during DN progression. This includes normalization of the levels of the suppressed antioxidants, SPD, Cx43 and EPO, and the DM-induced factors, MDA, GGT, vimintin, desmin, SREBP-1c, TGF- $\beta 1$ and iNOS. Clarification of the underlying mechanisms of curcumin activity may provide novel therapeutic targets for the treatment of DN.

\section{Acknowledgements}

The present work was supported in part by a research project grant (no. 1/434/2799) from Taif University. The authors are thankful to Associate Professor Samir Ahmed El-shzely, at the Department of Biotechnology, College of Science (Taif University) and to Dr Mohamed Abdo Nassan (Department of Pathology, Faculty of Veterinary Medicine, Zagazig University, Egypt) for their help with the practical part of the study. 


\section{References}

1. Gao Q, Shen W, Qin W, Zheng C, Zhang M, Zeng C, Wang S, Wang J, Zhu X and Liu Z: Treatment of db/db diabetic mice with triptolide: A novel therapy for diabetic nephropathy. Nephrol Dial Transplant 25: 3539-3547, 2010.

2. Forbes JM, Coughlan MT and Cooper ME: Oxidative stress as a major culprit in kidney disease in diabetes. Diabetes 57: 1446-1454, 2008.

3. Rossing P, Hougaard P and Parving HH: Risk factors for development of incipient and overt diabetic nephropathy in type 1 diabetic patients: A 10-year prospective observational study. Diabetes Care 25: 859-864, 2002.

4. Sawicki PT, Didjurgeit U, Mühlhauser I, Bender R, Heinemann L and Berger M: Smoking is associated with progression of diabetic nephropathy. Diabetes Care 17: 126-131, 1994.

5. Mühlhauser I, Bender R, Bott U, Jörgens V, Grüsser M, Wagener W, Overmann $\mathrm{H}$ and Berger M: Cigarette smoking and progression of retinopathy and nephropathy in type 1 diabetes. Diabet Med 13: 536-543, 1996.

6. De Cosmo S, Lamacchia O, Rauseo A, Viti R, Gesualdo L, Pilotti A, Trischitta V and Cignarelli M: Cigarette smoking is associated with low glomerular filtration rate in male patients with type 2 diabetes. Diabetes Care 11: 2467-2470, 2006.

7. Hallan SI and Orth SR: Smoking is a risk factor in the progression to kidney failure. Kidney Int 80: 516-523, 2011.

8. Winer S, Chan Y, Paltser G, Truong D, Tsui H, Bahrami J, Dorfman R, Wang Y, Zielenski J, Mastronardi F, et al: Normalization of obesity-associated insulin resistance through immunotherapy. Nat Med 15: 921-929, 2009.

9. Aggarwal BB, Sundaram C, Malani N and Ichikawa H: Curcumin: The Indian solid gold. Adv Exp Med Biol 595: 1-75, 2007.

10. Sharma S, Kulkarni SK and Chopra K: Curcumin, the active principle of turmeric (Curcuma longa), ameliorates diabetic nephropathy in rats. Clin Exp Pharmacol Physiol 33: 940-945, 2006.

11. Meghana K, Sanjeev G and Ramesh B: Curcumin prevents streptozotocin-induced islet damage by scavenging free radicals: A prophylactic and protective role. Eur J Pharmacol 577: 183-191, 2007.

12. Chiu J, Khan ZA, Farhangkhoee H and Chakrabarti S: Curcumin prevents diabetes-associated abnormalities in the kidneys by inhibiting p300 and nuclear factor-kappaB. Nutrition 25: 964-972, 2009.

13. Suvarna SK, Layton C and Bancroft JD (eds): The hematoxylins and eosin. In: Bancroft's Theory and Practice of Histological Techniques. 7th edition. Churchill Livingstone, London, pp172-186, 2013

14. Liu DG and Wang TM: Role of connective tissue growth factor in experimental radiation nephropathy in rats. Chin Med J (Engl) 121: 1925-1931, 2008.

15. Zheng CX, Chen ZH, Zeng CH, Qin WS, Li LS and Liu ZH Triptolide protects podocytes from puromycin aminonucleoside induced injury in vivo and in vitro. Kidney Int 74: 596-612, 2008.

16. Gu L, Gao Q, Ni L, Wang M and Shen F: Fasudil inhibits epithelial-myofibroblast transdifferentiation of human renal tubular epithelial HK-2 cells induced by high glucose. Chem Pharm Bull (Tokyo) 61: 688-694, 2013.

17. Lan X, Rai P, Chandel N, Cheng K, Lederman R, Saleem MA, Mathieson PW, Husain M, Crosson JT, Gupta K, et al: Morphine induces albuminuria by compromising podocyte integrity. PLoS One 8: e55748, 2013.

18. Benzing T: Signaling at the slit diaphragm. J Am Soc Nephrol 15: 1382-1391, 2004

19. Satriano J, Mansoury H, Deng A, Sharma K, Vallon V, Blantz RC and Thomson SC: Transition of kidney tubule cells to a senescent phenotype in early experimental diabetes. Am J Physiol Cell Physiol 299: C374-C380, 2010

20. Miyauchi M, Toyoda M, Kobayashi K, Abe M, Kobayashi T, Kato M, Yamamoto N, Kimura M, Umezono T and Suzuki D: Hypertrophy and loss of podocytes in diabetic nephropathy. Intern Med 48: 1615-1620, 2009.

21. Zheng M1, Lv LL, Ni J, Ni HF, Li Q, Ma KL and Liu BC: Urinary podocyte-associated mRNA profile in various stages of diabetic nephropathy. PLoS One 6: e20431, 2011.

22. Dousdampanis P, Trigka K and Fourtounas C: Prevalence of anemia in patients with type II diabetes and mild to moderate chronic kidney disease and the impact of anti-RAS medications. Saudi J Kidney Dis Transpl 25: 552-557, 2014.
23. Singh DK, Winocour P and Farrington K: Erythropoietic stress and anemia in diabetes mellitus. Nat Rev Endocrinol 5: 204-210, 2009.

24. Habek D, Habek JC, Ivanisević M and Djelmis J: Fetal tobacco syndrome and perinatal outcome. Fetal Diagn Ther 6: 367-371, 2002.

25. Gouva C, Nikolopoulos P, Ioannidis JP and Siamopoulos KC: Treating anemia early in renal failure patients slows the decline of renal function: A randomized controlled trial. Kidney Int 66: 753-760, 2004.

26. Martínez-Morúa A, Soto-Urquieta MG, Franco-Robles E, Zúñiga-Trujillo I, Campos-Cervantes A, Pérez-Vázquez V and Ramírez-Emiliano J: Curcumin decreases oxidative stress in mitochondria isolated from liver and kidneys of high-fat diet-induced obese mice. J Asian Nat Prod Res 15: 905-915, 2013.

27. Ishigaki N, Yamamoto T, Shimizu Y, Kobayashi K, Yatoh S, Sone H, Takahashi A, Suzuki H, Yamagata K, Yamada N and Shimano H: Involvement of glomerular SREBP-1c in diabetic nephropathy. Biochem Biophys Res Commun 364: 502-508, 2007.

28. Uttarwar L, Gao B, Ingram AJ and Krepinsky JC: SREBP-1 activation by glucose mediates TGF- $\beta$ upregulation in mesangial cells. Am J Physiol Renal Physiol 302: F329-F341, 2012.

29. Jun H, Song Z, Chen W, Zanhua R, Yonghong S, Shuxia L and Huijun D: In vivo and in vitro effects of SREBP-1 on diabetic renal tubular lipid accumulation and RNAi-mediated gene silencing study. Histochem Cell Biol 3: 327-345, 2009.

30. Basile DP: Transforming growth factor-beta as a target for treatment in diabetic nephropathy. Am J Kidney Dis 38: 887-892, 2001.

31. Lv S, Liu G, Sun A. G, Wang J, Cheng J, Wang W, Liu X, Nie H and Guan G: Mesenchymal stem cells ameliorate diabetic glomerular fibrosis in vivo and in vitro by inhibiting TGF- $\beta$ signalling via secretion of bone morphogenetic protein 7. Diab Vasc Dis Res 11: 251-261, 2014.

32. Seoane-Collazo P, Martínez de Morentin PB, Fernø J, Diéguez C, Nogueiras R and López M: Nicotine improves obesity and hepatic steatosis and ER stress in diet-induced obese male rats. Endocrinology 155: 1679-1689, 2014

33. Wen X, Zeng Y, Liu L, Zhang H, Xu W, Li N and Jia X: Zhenqing recipe alleviates diabetic nephropathy in experimental type 2 diabetic rats through suppression of SREBP-1c. J Ethnopharmacol 142: 144-150, 2012.

34. Luan J, Li W, Han J, Zhang W, Gong H and Ma R: Renal protection of in vivo administration of tempol in streptozotocin-induced diabetic rats. J Pharmacol Sci 119: 167-176, 2012.

35. Simsek N, Kaya M, Kara A, Can I, Karadeniz A and Kalkan Y: Effects of melatonin on islet neogenesis and beta cell apoptosis in streptozotocin-induced diabetic rats: An immunohistochemical study. Domest Anim Endocrinol 43: 47-57, 2012.

36. Akinola OB, Caxton Martins EA and Dini L: Chronic treatment with ethanolic extract of the leaves of Azadirachta indica ameliorates lesions of pancreatic islets in streptozotocin diabetes. Int J Morphol 28: 291-302, 2010.

37. Bruin JE, Kellenberger LD, Gerstein HC, Morrison KM and Holloway AC: Fetal and neonatal nicotine exposure and postnatal glucose homeostasis: Identifying critical windows of exposure. Journal of Endocrinology 194: 171-178, 2007.

38. Bruin JE, Petre MA, Lehman MA, Raha S, Gerstein HC, Morrison KM and Holloway AC: Maternal nicotine exposure increases oxidative stress in the offspring. Free Radic Biol Med 44: 1919-1925, 2008.

39. Abdul-Hamid M and Moustafa N: Protective effect of curcumin on histopathology and ultrastructure of pancreas in the alloxan treated rats for induction of diabetes. J Appl Zool 66: 169-179, 2013.

40. Ong AC, Jowett TP, Firth JD, Burton S, Kitamura M and Fine LG: Human tubular-derived endothelin in the paracrine regulation of renal interstitial fibroblast function. Exp Nephrol 2: 134, 1994

41. Soetikno V, Suzuki K, Veeraveedu PT, Arumugam S, Lakshmanan AP, Sone H and Watanabe K: Molecular understanding of curcumin in diabetic nephropathy. Drug Discov Today 18: 756-63, 2013.

42. Sassy-Prigent C, Heudes D, Mandet C, Bélair MF, Michel O, Perdereau B, Bariéty J and Bruneval P: Early glomerular macrophage recruitment in streptozotocin-induced diabetic rats. Diabetes 49; 466-475, 2000. 
43. Soetikno V, Sari FR, Veeraveedu PT, Thandavarayan RA, Harima M, Sukumaran V, Lakshmanan AP, Suzuki K, Kawachi $\mathrm{H}$ and Watanabe $\mathrm{K}$ : Curcumin ameliorates macrophage infiltration by inhibiting NF- $\kappa \mathrm{B}$ activation and proinflammatory cytokines in streptozotocin induced-diabetic nephropathy. Nutr Metab (Lond) 8: 35, 2001.
44. Asaba K, Tojo A, Onozato ML, Goto A, Quinn MT, Fujita T and Wilcox CS: Effects of NADPH oxidase inhibitor in diabetic nephropathy. Kidney Int 67: 1890-1898, 2005.

45. Goel A, Kunnumakkara AB and Aggarwal BB: Curcumin as 'Curecumin': From kitchen to clinic. Biochem Pharmacol 75: 787-809, 2008. 